\section{Application of the solvatochromic fluorescence of 8-(phenylamino)-1-naphthalenesulphonate in thin-layer chromatography of Picea abies epicuticular waxes}

\author{
S.H. Hüttenhain ${ }^{1}$, T. Euteneuer ${ }^{1,2}$, and R. Debus ${ }^{1}$ \\ 1 Fraunhofer Institut für Umweltchemie und Ökotoxikologie, \\ D-5948 Schmallenberg/Grafschaft, \\ Federal Republic of Germany \\ ${ }^{2}$ Institut für Pflanzenökologie der JLU Gießen, \\ Heinrich-Buff-Ring 38, D-6300 Gießen, \\ Federal Republic of Germany
}

\section{Anwendung der solvatochromen Fluoreszenz von 8-(Phenylamino)-1-naphthalinsulfonat bei der Dïnnschicht-Chromatographie von Epicuticular-Wachsen von Picea abies}

Luminescence properties of 8-(phenylamino)-1-naphthalenesulphonate (8,1-ANS) are of great theoretical interest [1] and their application as a fluorescence probe in biochemical studies is well documented [2]. We have investigated the dye as a reagent for staining the preparative thin-layer chromatogram of Picea abies epicuticular waxes.

The chemical composition of epicuticular waxes has been correlated successfully with needle age and microclimatic influences as well as with genetic composition [3-6]. We are attempting to develop correlations between the morphology [7] and the chemical composition of the waxes under the influence of different concentrations of air pollutants. While investigating and characterizing the waxes, we separated their components by thin-layer chromatography (TLC) according to their polarity and functional groups, respectively $[8,9]$. This was followed by extraction and subsequent gas chromatographic (GC) analyses of the fractions. Therefore, irreversible staining has to be avoided. Commercial fluorescing TLC-plates proved to be unsatisfactory because of the small amount of fluorescence quenching by the wax components. For the GC measurements, colouring the plates with an alcoholic solution of 8,1-ANS was the method of choice. The dye shows bright luminescence in organic solvents of low or medium polarity because of its solvatochromic behaviour. Conversely, there is little effect in polar media [1] or when the dye is absorbed on a polar surface (e.g. $\mathrm{SiO}_{2}$ ). When the plates are sprayed with the solution, the fluorescent substances are extracted into the wax components on the plates. After evaporation of the solvent the typical fluorescence of UV excitation can be observed by means of a normal TLC lamp $\left(\lambda_{\mathrm{ExC}}=366 \mathrm{~nm}\right)$. The different regions can be marked, collected, further extracted and analysed. No inter- ference of 8,1-ANS with the GC analyses could be detected in blanks under the experimental conditions.

\section{Experimental}

Needles of spruce (Picea abies L. Karst.) were harvested according to needle age classes from different measuring points. Epicuticular waxes from $10 \mathrm{~g}$ needles (FW) were extracted by shaking for $1 \mathrm{~min}$ in $5 \mathrm{ml} \mathrm{CHCl}$ (Merck). Wax yield was determined after filtration and evaporation. The crude wax $(\sim 50 \mathrm{mg})$ was dissolved in $\mathrm{CHCl}_{3}$. The wax was then separated into its principal fractions using preparative TLC (compare $[8,9]$ ) (PSC Kieselgel $60 \mathrm{~F}_{254} \mathrm{~S} / 2 \mathrm{~mm} /$ Merck) as follows: preparatory run of the plates in $100 \mathrm{ml} \mathrm{CHCl}_{3}$; first run in $100 \mathrm{ml}$ $\mathrm{CCl}_{4}$ to obtain alkanes; second run in $100 \mathrm{ml} \mathrm{CHCl}_{3}$ to separate esters, aldehydes, ketones and alcohols; third run in $100 \mathrm{ml}$ $\mathrm{CHCl}_{3} / 1 \% \mathrm{HOAc}$ to separate acids.

Fractions were made visible by spraying the plates with an $0.1 \mathrm{mmol}$ alcoholic solution of 8,1-ANS (Aldrich Chemical Company; used without further purification) and examined under a TLC lamp $\left(\lambda_{\mathrm{EXC}}=366 \mathrm{~nm}\right)$. Bands of the wax fractions were identified by comparison with analytical standards run on the plates. The wax for each class was scraped from the plate and extracted with $5 \mathrm{ml} \mathrm{CHCl}$. After filtration and subsequent evaporation, the wax yield was determined for each class.

The chemical compositions of the wax classes were investigated by GC (Carlo Erba Mega HRGC). Peak identification was by comparison with analytical standards or GC-MS [10].

\section{References}

1. Kosower EM, Kanety H (1983) J Am Chem Soc 105:6236

2. Azzis A (1975) A Rev Biophys 8:237

3. Günthardt-Goerg MS (1986) Eur J For Pathol 16:400408

4. Schuck HJ (1972) Flora 161:604-622

5. Tulloch AP (1987) Phytochemistry 26:1041-1043

6. Tulloch AP (1976) Chemistry and biochemistry of natural waxes. In: Kollattukudy PE (ed) Elsevier, pp 235-287

7. Euteneuer T, Steubing L, Debus R (1987) Angew Bot, in press

8. Bianchi G (1985) Genet Agrar 39:471 - 486

9. Holloway PJ, Challen SB (1966) J Chromatogr 25:336346

10. Euteneuer T, Steubing L, in preparation

Received September 3, 1987 